

INTERNATIONAL RESEARCH JOURNAL ON ADVANCED SCIENCE HUB

\title{
Linear quadratic gaussian control design with extended KALMAN filter
}

Priya Shree Madhukar', Praveen Kumar Mishra ${ }^{2}$

M.Tech Student ${ }^{12}$ Dept. of Electrical Engineering, Madan Mohan Malaviya University of Technology, Gorakhpur, Uttar Pradesh

priyashreemadhukar@gmail.com ${ }^{1}$,praveen.mishra590@gmail.com ${ }^{2}$

\section{Abstract}

Linear quadratic problems are fundamental problem of optimal control system. These are introduced in linear system by additive white Gaussian noise. This problem is overcome with help of linear quadratic Gaussian controller. Controller is combination of optimal estimator and Kalman Filter used to compensate the noises in system.The main prospective of paper to design a LQG with Extended Kalman Filter for position control of dc servo motor. The direct implementation of LQG with kalman filter is adapting to change system parameters. EKF allows values of parameter estimation with unknown state of system. ANN based technique are used to compare characteristic of the controller different parameters. To evaluate system characteristics with three techniques 1) ANN 2) LQG 3) Extended Kalman Filter.

\section{Keywords: Linear Quadratic Regulator, Kalman Filter, Extended Kalman Filter, State Estimation,} DC Servo Motor

\section{Introduction}

In control system The Kalman Filter is among the most remarkable developments of the twentieth century. This calculation recursively appraises the state factors the position and speed of a shot-in a boisterous straight dynamical framework by limiting the mean-squared estimation error of the present state as uproarious estimations are gotten and as the framework develops in time. Each update gives the most recent fair-minded state of the framework factors together with a measure on the vulnerability of those assessments as a covariance matrix. Since the refreshing procedure is genuinely broad and generally simple to register, the Kalman Filter can frequently be actualized progressively [4]. The Kalman Filter is extensive in the field of global positioning and navigation, radar, robotics, automotive control system and signal processing. In a purely numeric field such as neural network, it plays an important role in time series analysis.

Our way to improving the position of the servo motor using Extended Kalman Filter through the help of Linear Quadratic Gaussian control [5]. That Purpose of technique to overcome the position and speed of the dc servo motor due to sensor noise and disturbance of the plant in the system. The best way of the optimal control to facilitate position control in a dc servo motor with Extended Kalman Filter.

\subsection{Problem Statement}

A servo engines has got incredible consideration in late years. Contrast with other engine kind, servo engines is able to convey extra torque plus power used for a similar extent. Other than to it additionally gives secure and trustworthy operation and provides less upkeep which create the utilized of servo motor got an extraordinary consideration. 
In particular, with most recent advancement in chip and power gadgets, very precise and exceptionally proficient servo motor control frameworks have been created. The requirement for an input component was required so as to make control framework stable. More, the control exactness is legitimately relative exactness of servo motor manage. The exactness of servo motor control includes hard accomplishing because of the numbness of the workplace unsettling influence and errors during criticism estimation source of noise of sensor.

\subsection{Literature Review}

Perry A. et al. (1995) this paper exists relationship between discrete time kalman filter and LQ design in a SISO plant. In this design of kalman filter is possible through loop recovery transfer function.

R. Nikoukhah et al., (1996) in this paper discuss the method of stochastic descriptor systems. In this new method or algorithm change the system without changing the statistical properties (causality properties) of the system. It provides a answer to a problem of descriptor kalman filter.

John Sum et al., (1999) in this paper, displayed a technique on the best way to prune a neural system exclusively dependent on the outcomes gotten by Kalman filter preparing, for example, the weight vector $\hat{\theta}$ and $\mathrm{P}(\mathrm{N})$ the framework. With the suppositions that 1) the preparation unites and 2) $\hat{\theta}$ is near $\theta_{0}$ and the span of the preparation information is sufficiently extensive and determined a rich condition communicating such connection. Utilizing this condition, to evaluate the quantity of weight ought to be pruned and which weight ought to be pruned away.

L. Gargouri et al., (2002) in that paper using a mathematical concept to define necessary condition of the LQR/LTR synthesis. This approach is used to combine the use of state techniques and frequentally representation in a real time. That's way this combination is used to system with adaptive control.

Jesus M. Corres sanz et al., (2004) in this paper using new method to manage speed and disturbance of induction motor the major work of the method is to remove the noise due to encoder quantization. Frequency response of the system and the encoder noise are measure the observer LQR/LTR controller. Disturbance filter pattern are gives guidelines with the help of periodic filter output technique.

K. Rajgopal et al., (2006) in this paper a way to deal with plan a Neural Network based Extended Kalman Filter (NNEKF) with a repetitive neural model to assess the condition of a boisterous unique framework has been endeavoured. The adequacy of the proposed state estimator has been shown on a three tank benchmark framework. The re-enactment investigations of the three tank framework, it is construed that the NNEKF is observed to be a decent substitution to the regular EKF. The nonlinear state estimator created in this work can be utilized in nonlinear model based control plans, for example, inner model control and model predictive control.

Mohammadi S. et al., (2007) this paper gives utilization of modular arrangement to state estimation of nonlinear frameworks and presents another state estimation approach for nonlinear frameworks which utilizes a modular arrangement model of nonlinear frameworks for Kalman separating. The estimation error utilizing proposed technique has been contrasted and estimation mistake of established Kalman sifting. The examination infers that proposed technique is more powerful than the traditional Kalman separating. This methodology can have numerous applications with regards to nonlinear framework control.

Jose A. Rosendo et al., (2007) this paper exhibits another utilization of late created self-tuned Kalman Filter to low-pass through a filter stage required in some dynamic power filter calculations. Three techniques for low-pass filtering of APF control systems have been tried: the regular running normal, a routinely tuned Kalman filter and a selftuned Kalman filter. The significant part of Kalman filter responds quicker under transient conditions, especially when one tuned methodology is embraced.

Fredrick Gustafsson et al., (2012) in this paper attention to a few less known connections among EKF and UKF in term of two ideal various executions of the Kalman filter: the standard one dependent on the discrete Riccati condition, and one dependent on a recipe on contingent desires that does not include an express Riccati equation. First, 


\section{www.rspsciencehub.com}

it is demonstrated that the sigma point work assessments can be utilized in the traditional EKF as opposed to an unequivocally linearized model. Second, a less referred to form of the EKF dependent on a second-request Taylor extension is appeared to be firmly identified with UKF. For nonlinear filtering issue where the non linearity is serious contrasted with the earlier state information, the traditional EKF "stinks" contrasted with the UKF, which has been deduced in a substantial number of uses. Then again, for some standard sensor models, the UT performs great.

Francois Auger et al., (2013) the Kalman Filter have got enormous enthusiasm beginning the modern hardware network and have assumed a real job in a lot of designing area while 1970s, extending, lacking mortal thorough, direction estimation, state and parameter estimation meant for organise or determination, information combining, flag preparing, etc. the coordination of Kalman Filter variations of the Kalman Filter into mechanical frameworks isn't across the board used for two initial reasons, multifaceted nature of calculation contrasted and the traditional Luenberger eyewitnesses plus computational burden prerequisite to being installed arranged a light computational power workstation.

Qiang Li et al., (2015) this paper discusses reviews of ongoing improvements in relation to Kalman filter, Extended Kalman filter plus Unscented Kalman filter. Fundamental speculations of Kalman Filter being presented, plus benefits in addition of bad marks of them be investigated plus looked at. In this analyzed and compared the Kalman Filter, Extended Kalman Filter and Unscented Kalman Filter through different filtering methods.

Samia Allaoui et al., (2015) in this paper, the state and parameters estimation utilizing Extended Kalman Filter (EKF) is that its optimality is basically subject to the decision of the correct covariance lattices of state and estimation noise. So as to conquer this trouble, another methodology dependent on the utilization of the tuned EKF to estimate all the while the speed and rotor motion of an enlistment engine drive is proposed. This methodology will right off streamline the covariance lattices by the Particle Swarm Optimization (PSO) calculation and from that point forward, the estimations of these covariance frameworks are presented in the estimation loop.
Volume 02 Issue 06 June 2020

The PSO method to optimized the EKF performance, it empowers the noise covariance networks $\mathrm{Q}$ and $\mathrm{R}$, which legitimately influences the estimation execution, to be appropriately chosen. This estimation calculation was likewise tried under load torque and rotor opposition varieties of where better arrangement and great exhibitions were acquired.

\subsection{Overview of Kalman Filter}

Kalman filter are used in many areas but it is efficiently used in predication and estimation of the estimators.

- First it highly used in dynamic system for state estimation: almost everything is dynamics in world expect some physical constraints which are fundamental constant in universe. We know that everything is not précised in nature so it is very difficult to know the precision of any dynamical models. One method which expresses our ignorance better precisely is probability.

- Second is estimated system analysis: in this we focus on the designing of the sensor types to use very well in a given area of the sensor in set of design criteria. A term criterion is related to system cost and estimation accuracy below given table shows the stat estimation of the dynamic system in a column third.

Optimal filter gain in a Kalman Filter is obtained with the help of probability distribution of estimation inaccuracy; this probability distribution is used to describe the blueprint parameters of the estimation procedure. It depends upon parameters which are-

- Type of sensor is used

- Orientation and location of different types of sensor with concerning to estimated system

- Sensors characteristics regarding to permissible noise

- Methods of prefiltering in sensor for smoothing noise

- Sensors data sampling rates

- Easy simplification to reduce implementation requirements. 


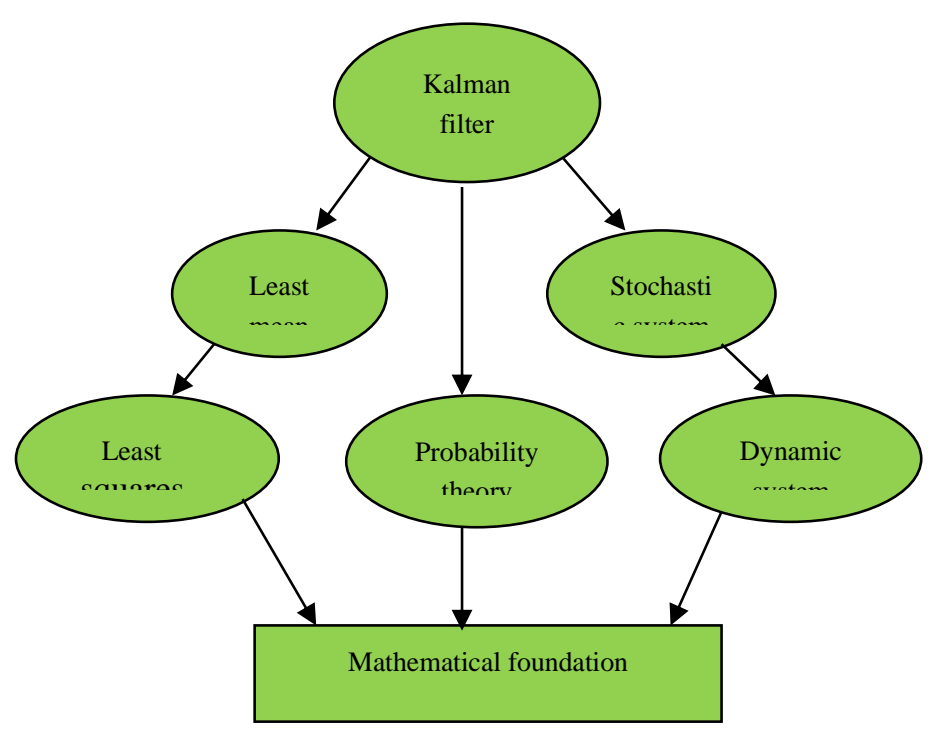

Fig.1. Mathematical Foundation of Kalman Filter

$$
\begin{aligned}
\dot{x}(t) & =A u(t)+B x(t)+K m(t) \\
y(t) & =C u(t)+p(t)
\end{aligned}
$$

$x(t) \in \mathfrak{R}^{m}=$ input vector

$y(t) \in \mathfrak{R}^{P}=$ measured output vector

$\mathrm{A}, \mathrm{B}, \mathrm{C}, \mathrm{D}=$ dimensions of matrix

$$
\begin{aligned}
& m_{h}=\mathrm{N}\left(0, Q_{h}\right) \\
& p_{h}=\mathrm{N}\left(0, R_{h}\right)
\end{aligned}
$$

Assumed it is uncorrelated,

$$
E\left[\begin{array}{cc}
w_{h} w_{h}^{T} & w_{h} v_{h}^{T} \\
v_{h} w_{h}^{T} & v_{h} v_{h}^{T}
\end{array}\right]=\left[\begin{array}{cc}
Q_{h} & 0 \\
0 & R_{h}
\end{array}\right]
$$

Initial values are,..

$$
\begin{gathered}
x_{0}=E\left[x_{0}\right] \\
P_{0}=E\left[\left(x_{0}-\hat{x}_{0}\right)\left(x_{0}-\hat{x}_{0}\right)\right]
\end{gathered}
$$

Where, $\mathrm{P}_{0}$ is initial value of estimation error covariance $\mathrm{P}_{\mathrm{h}}$.

$$
\begin{aligned}
& \hat{x}_{h+1 / h}=A_{h} \hat{x}_{h / h}+B_{h} u_{h} \\
& P_{h+1 / h}=A_{h} P_{h / h} A_{h}^{T}+K_{h} Q_{h} K_{h}^{T}
\end{aligned}
$$

New filtered estimated values are-

$$
K_{F}=P_{h / h-1} C_{h}^{T}\left(C_{h} P_{h / h-1} C_{h}^{T}+R_{h}\right)^{-1}
$$

$$
\begin{gathered}
\hat{x}_{h / h}=\hat{x}_{h / h-1}+K_{F}\left(y_{h}-C_{h} \hat{x}_{h / h-1}\right) \\
P_{h / h}=\left[I-K_{F} C_{h}\right] P_{h / h-1} \\
\mathrm{~K}_{\mathrm{f}}=\text { Kalman Gain }
\end{gathered}
$$

At that time effectively tuned Kalman Filter must gave an exact estimation of state $\mathrm{x}_{\mathrm{h}}$ known the output $\mathrm{y}_{\mathrm{h}}$, this kind of arrangement is regularly used to take off noise in filter.

Table.1. Application of Kalman Filter

\begin{tabular}{|c|c|c|}
\hline Application & $\begin{array}{c}\text { Dynamic } \\
\text { system }\end{array}$ & Sensors types \\
\hline $\begin{array}{c}\text { Flood } \\
\text { predication }\end{array}$ & River system & $\begin{array}{c}\text { Weather radar } \\
\text { Water level } \\
\text { Rain gauge }\end{array}$ \\
\hline Tracking & Spacecraft & $\begin{array}{c}\text { Imaging system } \\
\text { Radar }\end{array}$ \\
\hline Navigation & Ship & $\begin{array}{c}\text { Gyroscope } \\
\text { Log } \\
\end{array}$ \\
& & $\begin{array}{c}\text { Accelerometer } \\
\text { GPS receiver }\end{array}$ \\
\hline
\end{tabular}

\subsection{Application of Artificial Neural Network in Kalman Filter}

Artificial Neural Networks be ground-breaking strategy use for understanding difficult dynamic frameworks. Developing artificial neural system begun by early comprehension of human sensory system in 1800 's, afterwards researchers began to include additional clear picture of how sensory system resembles, and later in twentieth century proposed principal Neuron model. While we address in relation to neural systems we have to convey their conduct to genuine organic neural framework that exist, which comprises of neuron cell, axons plus neurotransmitters. Neurons go about as handling components; they get message however axons process it with after that resends one more message to following neuron. Message initially is gotten by neural connections, which delivers a few sort of synthetic compounds call synapses.

ANN formation comprises various neurons associated each other; every neuron have comparable structure to different neurons. 
Every neuron consisting weight (w), transfer function (f), bias (b) and output y. Output of neuron $\mathrm{y}$ be able to written regarding different components (Hagan, 1996)

$$
y=f\left(w_{a}+b\right)
$$

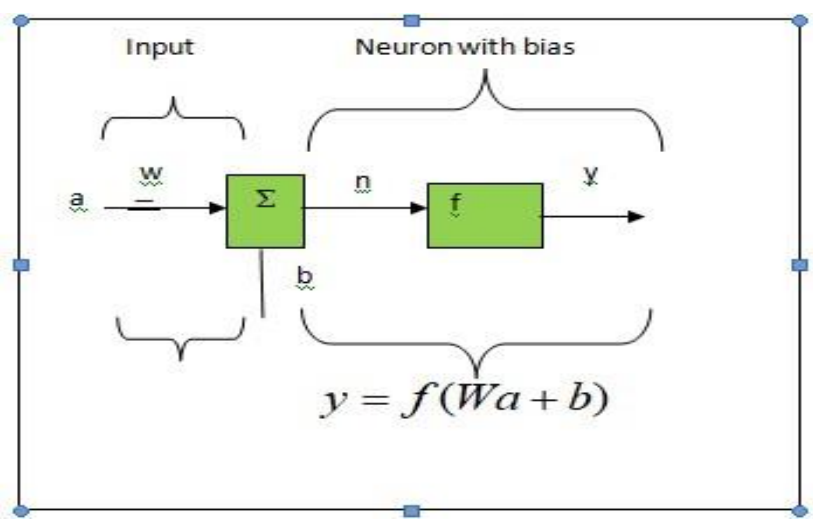

Fig.2. Structure of Artificial Neuron

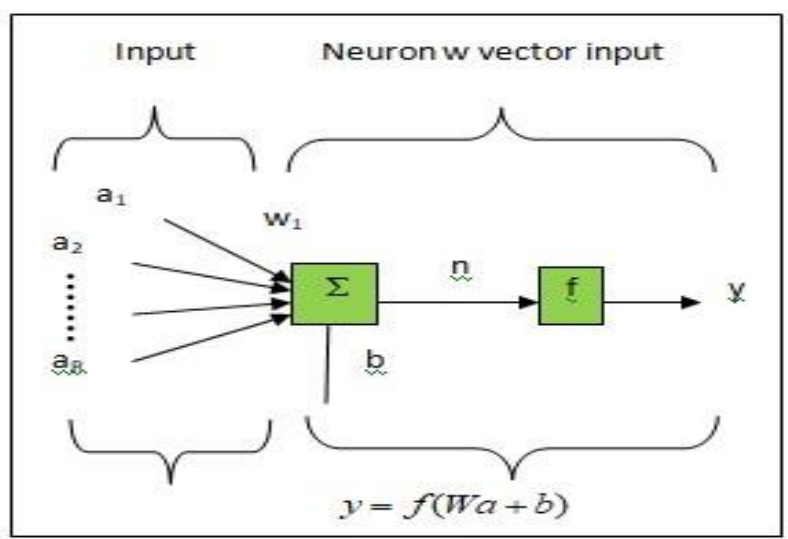

Fig.3. Neuron in Multilayer Input

Back propagation technique attempts to refresh the estimations of the weight and biases in the same heading as the execution function decreases all the more quickly. The condition that indicates how back propagation functions is-

$$
x_{k+1}=x_{k}+a_{k} g_{k}
$$

\section{LQG Controller Design for DC Servo Motor}

A design of LQG controller with help of Extended Kalman Filter, Here we using a third order system to designing of the LQG. Application to be used in this system is DC SERVO MOTOR system, in their controlling of the position of the servo motor with using extended Kalman Filter. In previous research was focused on speed and position of servo motor with Kalman Filter but we try to compute the position of dc servo motor with Extended Kalman Filter. Servo motor to control position and speed of closed loop arrangement easily. In control system feedback are play important role to stabling the system. When it used in the servomotor it cannot even increases cost of the system but too deign complex structure of position and speed. We know that the precision of servo motor is directly proportional to the control accuracy. Because of that the precision of the servo motor was not easy to estimate it due to feedback measurement inaccuracies and disturbance of the sensor noises.

\subsection{Mathematical Model of Dc Servo Motor}

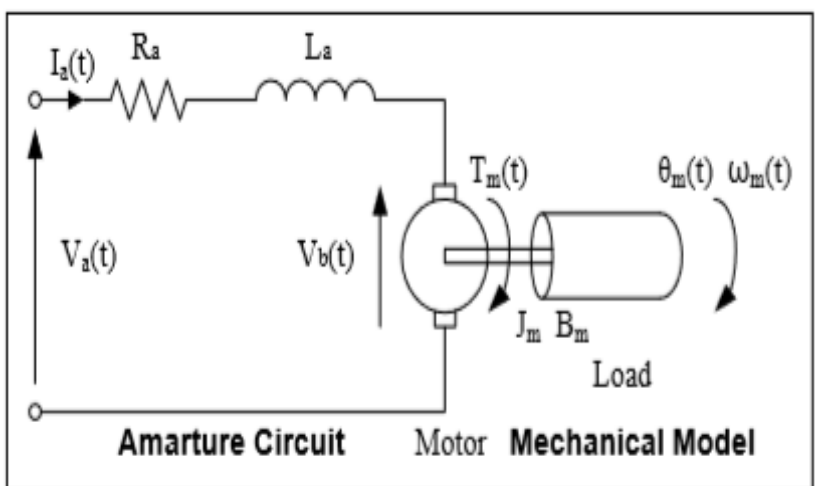

Fig.4. Model of DC Servo Motor

\subsubsection{Differential equations of the Dc Servo motor model:-}

1) Back emf in armature circuit-

$$
\mathrm{v}_{\mathrm{b}}=\mathrm{K}_{\mathrm{e}} \cdot \omega
$$

2) Torque of the motor-

$$
\mathrm{T}_{\mathrm{m}}=\mathrm{K}_{\mathrm{t}} \cdot \mathrm{i}(\mathrm{t})
$$

3) Kirchhoff voltage law in armature circuit -

$$
\mathrm{v}=\operatorname{Ri}(\mathrm{t})+\mathrm{L} \frac{\mathrm{di}(\mathrm{t})}{\mathrm{dt}}+\mathrm{v}_{\mathrm{b}}
$$

4) Newton's law-

$$
\mathrm{T}=\mathrm{J}_{\mathrm{m}} \cdot \theta^{\prime \prime}+\mathrm{T}_{\mathrm{L}}+\mathrm{b}_{\mathrm{m}} \cdot \theta^{\prime}
$$

\subsubsection{Transfer function:-}

Design a block figure of system main variables of the framework are-

$\mathrm{V}_{\mathrm{a}=\text { system input }}$

$\theta=$ system output

$\mathrm{T}_{\text {load }}=$ system disturbance element 
From equation (18) and (17)-

$V_{a}=R_{a}^{i}(t)+L_{a} \frac{d i_{a}(t)}{d t}+V_{b}$

Appling Laplace transformation in above equation-

$V_{a}(s)-K \Omega(s)=\left(R_{a}+L_{a} s\right) I_{a}(s)$

$I_{a}(s)=\frac{V_{a}(s)-K . \Omega(s)}{\left(L_{a}(s)+R_{a}\right)}=\left[V_{a}(s)-K . \Omega(s)\right] \times \frac{1}{\left(L_{a}(s)+R_{a}\right)}$

Now using equation (17) -

$T_{m}(s)=K . I_{a}(s)$

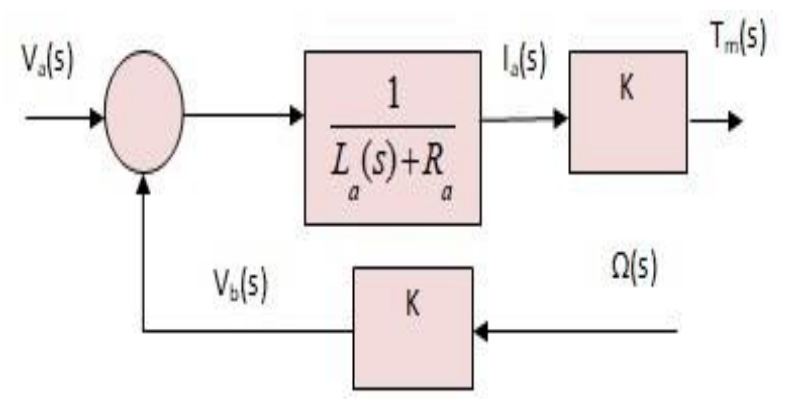

Fig.5.Transfer Function Model of Armature Control

To compute the output of the system using equation (4)-

$\mathrm{T}=\mathrm{J}_{\mathrm{m}} \cdot \theta^{\prime \prime}+\mathrm{T}_{\mathrm{L}}+\mathrm{b}_{\mathrm{m}} \cdot \theta^{\prime}$

Here, $\theta^{\prime \prime}=\mathrm{s}^{2}$

$$
\theta^{\prime}=\mathrm{s}
$$

Laplace transformation is used to analyze system in block diagram: -

$\mathrm{T}(\mathrm{S})=\mathrm{J}_{\mathrm{m}} \cdot \mathrm{s}^{2} \cdot \theta(\mathrm{s})+\mathrm{T}_{\mathrm{L}}+\mathrm{b}_{\mathrm{m}} \cdot \mathrm{s} \cdot \theta(\mathrm{s})$

$\mathrm{T}(\mathrm{S})-\mathrm{T}_{\mathrm{L}}=\mathrm{S}\left(\mathrm{J}_{\mathrm{m}} \cdot \mathrm{S}+\mathrm{b}_{\mathrm{m}}\right) \cdot \theta(\mathrm{s})$

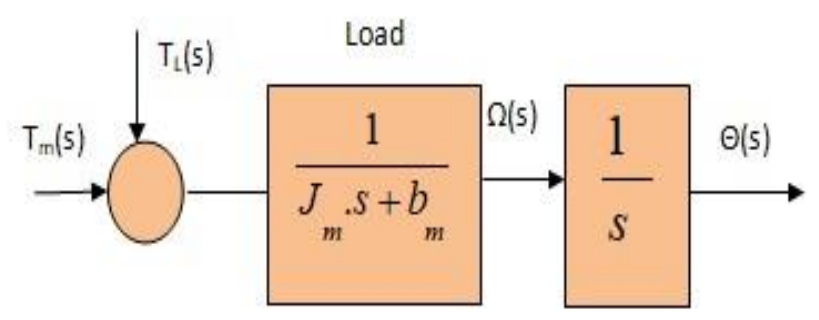

Fig.6. Transfer Function Model of Motor control

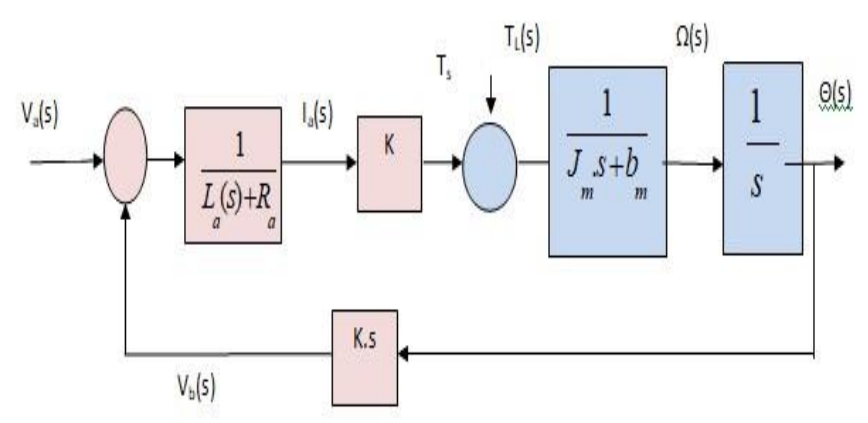

Fig.7. Block Diagram of open Loop System

Now consider $T_{L}=0$ (without load) then the eq. will be -

$$
\theta(s)=\left(\frac{1}{L_{a} s+R_{a}} \cdot K \cdot \frac{1}{J_{m} s+b_{m}} \cdot \frac{1}{s}\right) \cdot\left(V_{a}(s)-K \cdot s \cdot \theta(s)\right)
$$

$$
\frac{\theta(s)}{V_{a}(s)}=\frac{k}{s\left(\left(L_{a} s+R_{a}\right)\left(L_{m} s+b_{m}\right)+k^{2}\right)}
$$

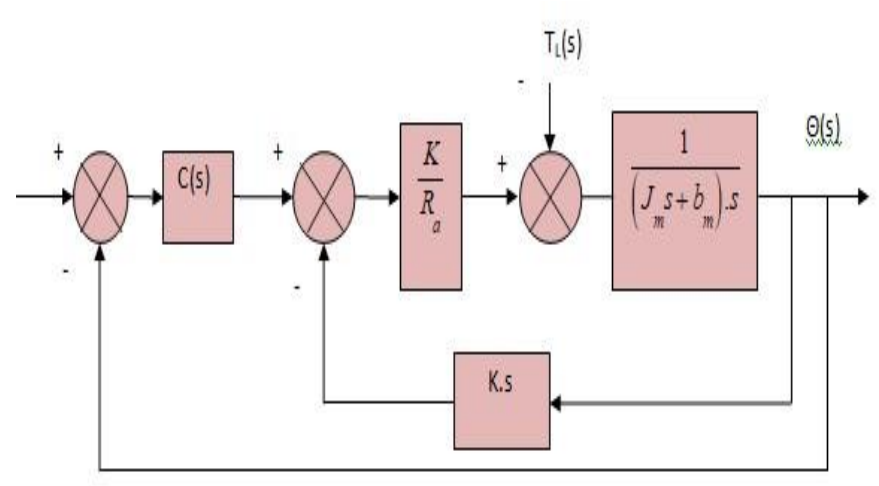

Fig.8. Dc servo motor closed loop transfer function block diagram 


\section{www.rspsciencehub.com}

To provide an easy task in a given system to reduce structure of given system to analysis of captured major characteristics.

In an initial step, the $T_{L}(s)$ is expelled from the minor input (green in colour), to be capable further to take out this minor error.

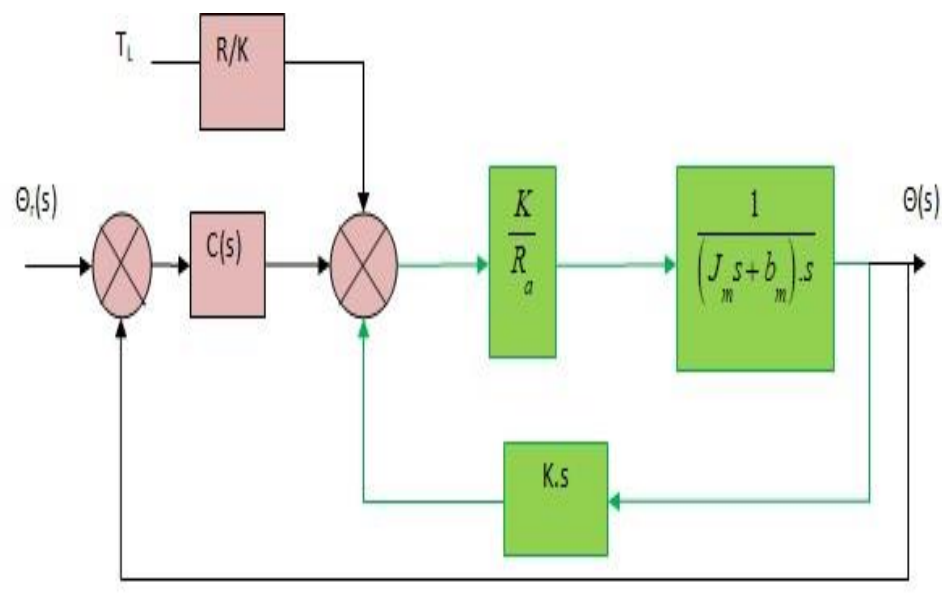

Fig.9. Reduce green area in a open loop transfer function

$$
\frac{\frac{K}{R_{a}\left(J_{m} \cdot s+b_{m}\right) \cdot s}}{1+\frac{K}{R_{a}\left(J_{m} \cdot s+b_{m}\right) \cdot s} \cdot K \cdot s}=\frac{K}{R_{a} \cdot J_{m} \cdot s^{2}+\left(K^{2}+R_{a} b_{m}\right) \cdot s}
$$

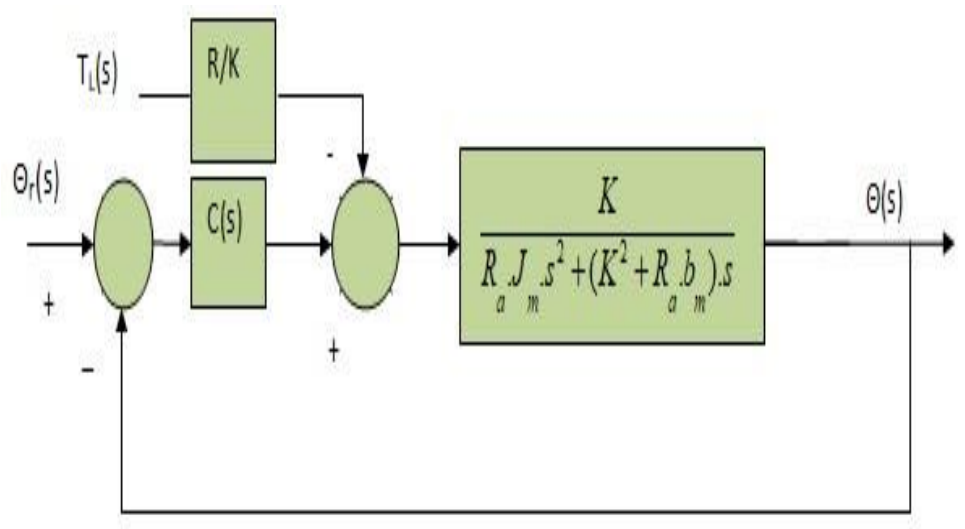

Fig.10. closed loop simplified transfer function in block diagram

\subsubsection{LQG Controller}

Linear Quadratic Gaussian Controller is an ideal state estimation system calling as Kalman filtering are considering to estimates the actual condition of a plant from data that is accessible concerning the plant.

In this framework using Discrete Kalman Filter based on third order system to structure LQG
Volume 02 Issue 06 June 2020

controller of DC servo motor. State estimation of Kalman Filter was additionally worked by Lagrange multiplier iteration by utilizing MATLAB M-File perspective just as LQ ideal control.



Fig.11. LQG controller

\section{Simulation and Results}

\section{ANN Based Dc Servo Motor}

ANN based dc servo motor is fabricated in neural system that has same capacity as the servomotor, input/output information sets used to prepare this system and simulate it. Here, main aim to construct SIMULINK model that speaks to the servomotor framework.

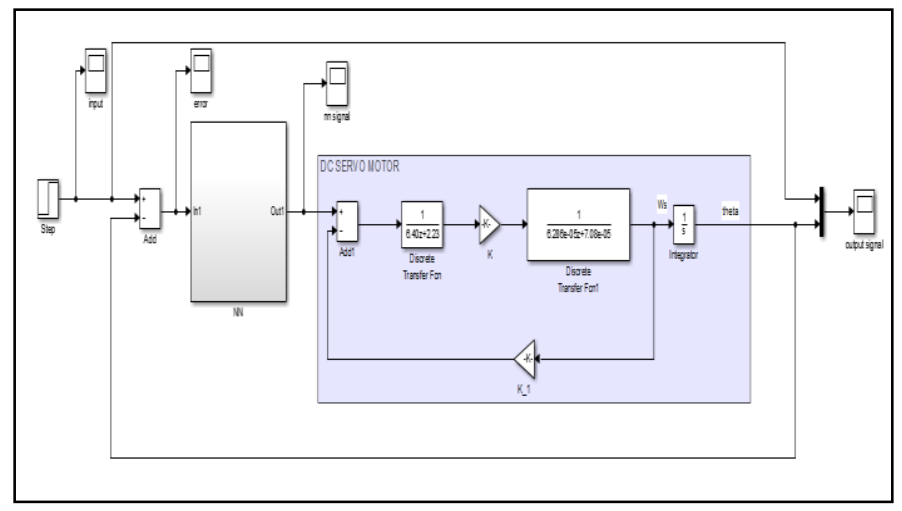

Fig.12. Matlab Simulink Model of ANN Based Dc Servo Motor

The input/yield information sets are produced from this model so as to prepare the Neural System 
model. The information is sent to $\mathbf{M}$ documents as matrix, put away in a predetermined area, when we required this information we used it well for further works. The model takes 10 seconds for simulating to produce the information. with help of a predefined step wave recurrence of $6 \mathrm{rad} / \mathrm{sec}$.

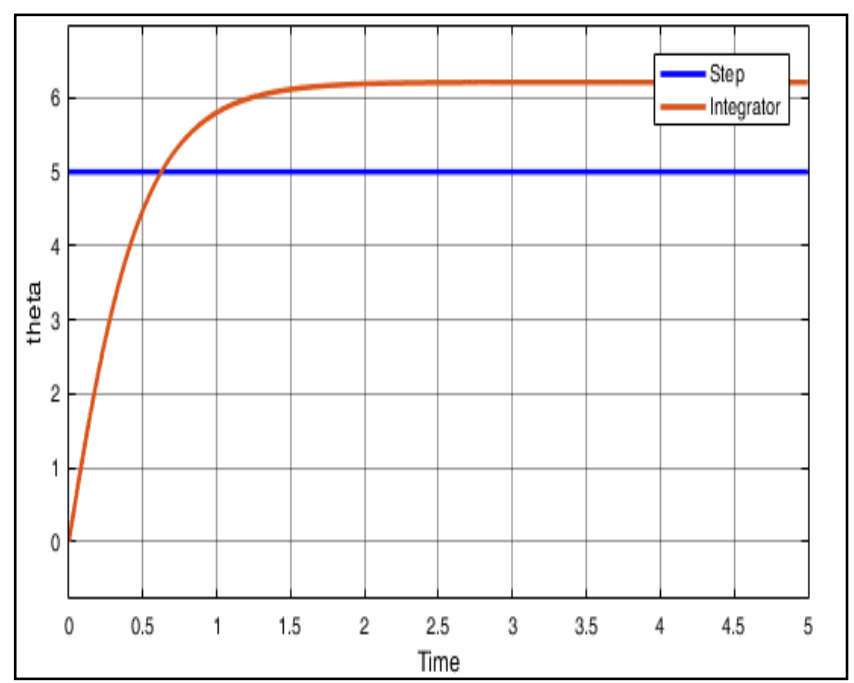

Graph.1. output waveform of ANN dc servo motor

We can verify that the output signal is does not matching the controller output; which confirms that the system is not well controlled. The output speed is not completely matching the controller signal.

Table.2.Parameters of system

\begin{tabular}{|c|c|}
\hline $\begin{array}{c}\text { State level tolerance } \\
(\%)\end{array}$ & 2.00 \\
\hline $\begin{array}{c}\text { Upper reference level } \\
(\%)\end{array}$ & 90.00 \\
\hline $\begin{array}{c}\text { Mid reference level } \\
(\%)\end{array}$ & 50.00 \\
\hline $\begin{array}{c}\text { Lower reference level } \\
(\%)\end{array}$ & 0.00 \\
\hline Settle seek(s) & 0.02 \\
\hline
\end{tabular}

\section{LQR +Kalman Filter based Dc Servo Motor}

In Simulink model of digital control to control position. The control framework of LQG controller has been utilized to control situation of the DC servo motor with solidarity input.
Fig.13. simulation model of LQR+ Kalman Filter with de servo motor

Unit step input was utilized is given this control framework to ensure the framework simple to create, adequately empower to give valuable data on both graph-2 given below the transient response and the steady state response for the framework.

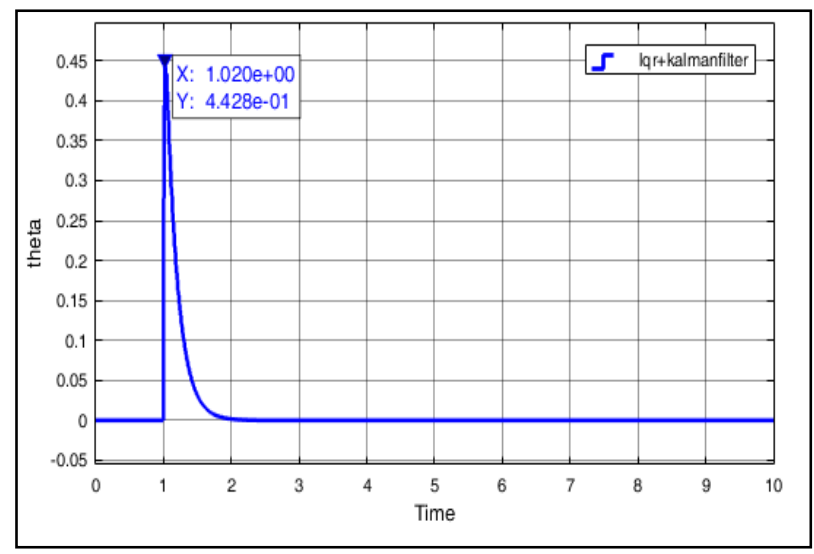

Graph.2. LQG waveform

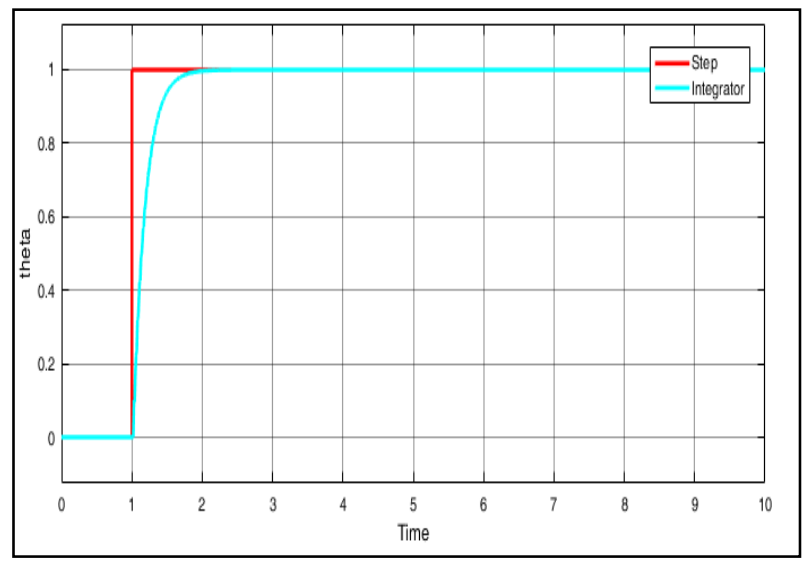

Graph.3. output wave form of LQG with de servo motor

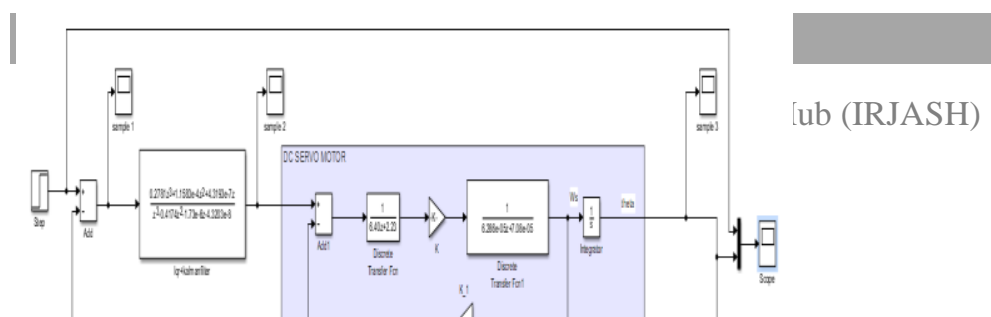




\section{www.rspsciencehub.com}

In view of graph.3 the closed loop control framework to control position has zero greatest overshoot which legitimately shows the overall stability of the framework.

Table.3.Signal statics

\begin{tabular}{|c|c|c|}
\hline & Value & time \\
\hline maximum & $1.000 \mathrm{e}+00$ & 5.930 \\
\hline minimum & $0.000 \mathrm{e}+00$ & $0.000 \mathrm{e}+00$ \\
\hline $\begin{array}{c}\text { Peak to } \\
\text { peak }\end{array}$ & $1.000 \mathrm{e}+00$ & \\
\hline Mean & $9.795 \mathrm{e}-01$ & \\
\hline Median & $1.000 \mathrm{e}+00$ & \\
\hline RMS & $9.853 \mathrm{e}-01$ & \\
\hline
\end{tabular}

Table.4.Parameters of system

\begin{tabular}{|c|c|}
\hline Rise time & $365.482 \mathrm{~ms}$ \\
\hline Slew rate & $2.167(/ \mathrm{s})$ \\
\hline Amplitude & $9.900 \mathrm{e}-01$ \\
\hline Edge & 1 \\
\hline Peak time & 0.030 \\
\hline Peak & $1.012 \mathrm{e}-01$ \\
\hline Settling maximum & 1 \\
\hline Settling minimum & 0 \\
\hline Overshoot & $0.501 \%$ \\
\hline Undershoot & $1.906 \%$ \\
\hline
\end{tabular}

\section{Extended Kalman Filter based Dc Servo Motor}

The LQG controller with help of Extended Kalman Filter is here we using a third order system to designing of the LQG. Application to be used in this system is DC SERVO MOTOR system, in their controlling of the position of the servo motor with using extended Kalman Filter. In previous research was focused on speed and position of servo motor with Kalman Filter but we try to compute the position of de servo motor with Extended Kalman Filter. Servo motor is used to control position and speed of closed loop arrangement easily.

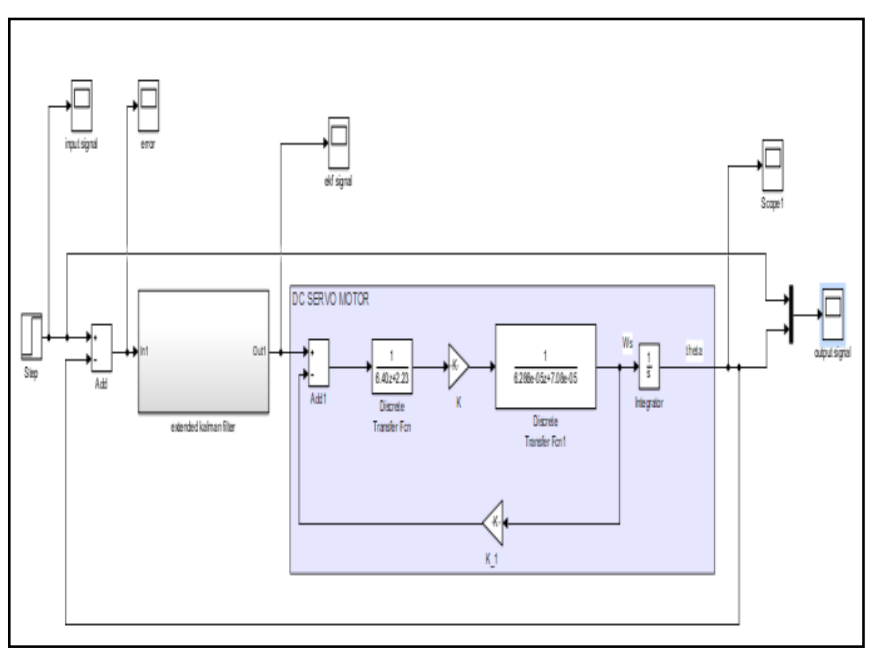

Fig.14. Simulink model of Extended Kalman Filter

In above Simulink model using same equation to verify the output of the system with respect to Extended Kalman Filter.

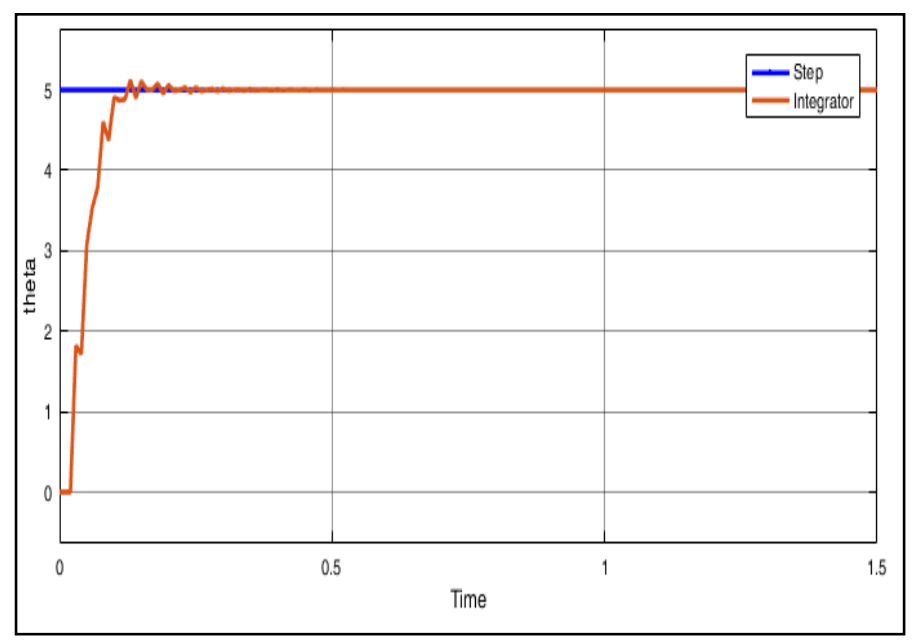

Graph.4. output waveform of Extended Kalman Filter with Dc Servo Motor

In Extended Kalman filter with dc servo motor in there some noises are disturbed position of the servo motor. The error between the actual signal actual signal and desired signal should be little bit compare to the ANN based dc servo motor.

Above result shows that ANN based dc servo motor not best solution to makeup with position control. Whereas Extended Kalman Filter also given error compare to LQR + Kalman Filter based system provides good result but some parameters of system are better in case of Extended Kalman Filter based system.

Table.5. signal statics 


\begin{tabular}{|c|c|c|}
\hline & Value & Time \\
\hline maximum & $5.122 \mathrm{e}+00$ & 0.130 \\
\hline minimum & $0.000 \mathrm{e}+00$ & $0.000 \mathrm{e}+00$ \\
\hline Peak to peak & $5.000 \mathrm{e}+00$ & \\
\hline Mean & $4.788 \mathrm{e}-01$ & \\
\hline Median & $5.000 \mathrm{e}+00$ & \\
\hline RMS & $4.871 \mathrm{e}+00$ & \\
\hline
\end{tabular}

Table.6. parameters of system

\begin{tabular}{|c|c|}
\hline Rise time & $55.827 \mathrm{~ms}$ \\
\hline Slew rate & $71.197(/ \mathrm{s})$ \\
\hline Amplitude & $4.968 \mathrm{e}+00$ \\
\hline Edge & 1 \\
\hline Peak time & 0.130 \\
\hline Peak & $5.122 \mathrm{e}+00$ \\
\hline Settling maximum & 1 \\
\hline Settling minimum & 0 \\
\hline Overshoot & $2.501 \%$ \\
\hline Undershoot & $2.471 \%$ \\
\hline
\end{tabular}

\section{Conclusion}

As the conclusion, Linear Quadratic Gaussian controller is design with extended kalman filter. The controller has been designed based on the dc servo motor to control the position of the motor. In their three comparisons are performed to describe which the best one to provide a better result is.

The first approach is ANN based dc servo motor the result obtain is not satisfied the desired signal does not follow the actual signal. The magnitude of the signal is higher which get some error in the system. The second approach is LQR + kalman filter this should satisfied an overall conditions of the system. The desired signal is followed by the actual signal in the system. There is no error between the estimated results. The third approach is extended kalman filter with dc servo motor in there some noises are disturbed position of the servo motor. The error between the actual signal and desired signal should be little bit compare to the ANN based dc servo motor.

So the LQG with Extended kalman filter provides the better result compare to ANN based dc servo motor. It is provides precisions in the position of the dc servo motor control.

\section{Acknowledgement}

It is pleasure to express my thanks to my supervisor Dr. L. B. Prasad for his guidance from basic to end phase. I also thanks to my friend to provide me moral support.

\section{References}

\section{Journals}

[1] W.M. Wan Syahidah, O. Rosli, M.A. Joraimee, A. Norhidayah, "Linear Quadratic Gaussian (LQG) Controller Design for Servo Motor" Australian Journal of Basic and Applied Sciences, 8(4) Special 2014, Pages: 700-713.

[2] N.J. Gordon, D.J. Salmond, A.F.M. Smith, "Novel approach to nonlinear/nonGaussian Bayesian state estimation", IEEE proceedings-F, vol.140, no.2, 1993, pp.10711.

[3] A.V. Shenoy, J. Prakash, V. Prasad, S.L. Shah, K.B. McAuley, "Particle issues in State Estimation using particle filters: Case Studies with polymer reactors", Elsevier Journal of process control, 2012. 45, no. 11, pp. 2182-2188, Nov. 2000.

[4] H. Won and K. Gunaratne, "Performance study of LQG, and risk sensitive control methods for satellite structure control," in American Control Conference, 200 Proceedings of the 2002, vol. 3, pp. 24812486 vol.3.

[5] Kalman, Rudolph Emil. "A new approach to linear filtering and prediction problems [J]." Journal of basic Engineering 82, no. 1 (1960): 35-45.

[6] Hmida, F. Ben, Karim Khémiri, José Ragot, and Moncef Gossa. "Three-stage Kalman filter for state and fault estimation of linear stochastic systems with unknown inputs." Journal of the Franklin Institute 349, no. 7 (2012): 2369-2388.

[7] An. Engelke, Hansellmann, and Herberat. "The LQG-control of highly resonant disc drive head the head positioning actuator." IEEE Transactions on the 
Industrial Electronical 36, no. 1 (1988): 101-104.

[8] Auger, François, Mickael Hilairet, Josep M. Guerrero, Eric Monmasson, Teresa Orlowska-Kowalska, and Seiichiro Katsura. "Industrial applications of the Kalman filter: A review." IEEE Transactions on Industrial Electronics 60, no. 12 (2013): 5458-5471.

[9] Spall, James C. Introduction to stochastic search and optimization: estimation, simulation, and control. Vol. 65. John Wiley \& Sons, 2005.

[10] Chen, Zheng, Yuhong $\mathrm{Fu}$, and Chunting Chris Mi. "State of charge estimation of lithium-ion batteries in electric drive vehicles using extended Kalman filtering." IEEE Transactions on Vehicular Technology 62, no. 3 (2012): 1020-1030.

[11] L. Campabell, Nikkoukhah, François Delebecque, and Ramin. "Kalman filtering for a general linear discrete-time systems." IEEE Transactions on Automatic Control system 45, no. 10 (1999): 18301839.

[12] Glielmo, Luigi, Roberto Setola, and Francesco Vassca. "An interlocked extended kalman filter." IEEE Transactions on automation control 44, no. 9 (1999): 1546-1549.

\section{Books}

[13] Welch, Greg, and Gary Bishop. "An introduction to the Kalman filter." (1995): 41-95.

[14] Grewall, Mohinnder S. Kalman filtering. Springer Berlin Heidelberg, 2012

[15] John B. Moore, Anderson, Brian DO, Optimal filtering in Courier Corporation, 2012.

[16] Simon, Daniel J. "Training fuzzy systems with the extended Kalman filter." Fuzzy sets and systems 132, no. 2 (2002): 189.

\section{Chapter in a Book}

[17] Julier, Simon J hey, Jeffrey R. Uhlmann. "New extension of Kalman filters to the nonlinear systems." Signal processing, target recognition VI, vol. 3058, pp. 181-193. International Society for Optics and Photonics, 1998.

\section{Conference Proceedings}

[18] Tzou, Hsiiang Jui, and Wuo Ying Yu. "The LQG/LTR control of an AC induction motor servo drive." IEEE Transactions on Power Electronics and drive 10, no. 3 (1995): 214-221.

[19] Kim-Hung Li, "Pool size Selection Sampling/Importance Sampling Algorithm", Statistica sinica, vol.17, pp.895-907, 2007. Bart Vandewoestyne, Ronald Cools, "Quasi-Random Sampling Importance Resampling and its convergence" IUAP DYSCO study of day, 22th November 2001.

[20] H. Zhou, "DC Servo Motor PID Control in Mobile Robots with Embedded DSP," in Proc. International Conference on Intelligent Computation Technology and Automation, 2008, pp. $332-336$.

[21] Aguila, R.C., Carazo, A.H., Perez, J.L.: 'Extended and unscented filtering algorithms in nonlinear fractional order systems', Appl. Math. Sci., 2012, 6, (30), pp. 1471-1486

[22] Sadeghian, H., Salarieh, H.: 'On the general Kalman filter for discrete time stochastic fractional systems', Mechatronics, 2013, 23, (7), pp. 764-771.

[23] D. Simon, "Training Fuzzy systems with the Extended Kalman Filter," IEEE Trans. on Fuzzy sets and systems, vol. 132, pp. 189-199, 2002.

[24] Abdelrahem, Mohamed, Christoph, Rallph Kenel. "Application of an extended Kalman filter to its parameter state estimation of double-fed induction generators in a variable speed wind turbine system." In 2016 International Conference on Clean Electrical Power (ICCEP), pp. 226-233. IEEE, 2016.

[25] Auger, Teresa Orlowska, François, Mickaël Hillairet, Seiichiiro Katssura, Eriic Monmason, Jossep M. Guerrer. 
"Introduction to the special section on industrial applications and implementation issues of the Kalman filter." IEEE Transactions on Industrial Electronics 60, no. 11 (2012): 4165-4168.

[26] Arulampalam, M. Sanjeev, Simon Haskell, Neil Bordon, and Tim Capp. "An tutorial on the particle filters for online non-Gaussian Bayesian tracking." IEEE Transactions on a signal processing 50, no. 2 (2003): 174$188 \mathrm{I}$.

[27] Borsje, Pieter, S. L. Hoo, T. F. Chhan, Y. K. Wonhg. "A comparative studing of the Kalman filtering for sensorless control of drive permanent-magnet synchronous motor." in IEEE International Conference on Electric Drives and Machines, 2006., pp. 815-822. IEEE, 2006.

[28] Iwasaki, Tetsuya, and Teruo Kataoka. "The Application of an extended Kalman filter and its parameter identification of an induction motor." in Conference of the IEEE Industrial Applications of Society, pp. 249-254. IEEE, 1989. 